\title{
The Insulin Receptor Mediates Insulin's Early Plasma Clearance by Liver, Muscle, and Kidney
}

\author{
Rick I. Meijer (D) and Eugene J. Barrett*(D) \\ Division of Endocrinology, Department of Medicine, University of Virginia Health Care System, \\ Charlottesville, VA 22908, USA; r.meijer@amsterdamumc.nl \\ * Correspondence: ejb8x@virginia.edu
}

check for updates

Citation: Meijer, R.I.; Barrett, E.J. The Insulin Receptor Mediates Insulin's Early Plasma Clearance by Liver, Muscle, and Kidney. Biomedicines 2021, 9, 37. https://doi.org/10.3390/ biomedicines 9010037

Received: 14 December 2020 Accepted: 2 January 2021 Published: 5 January 2021

Publisher's Note: MDPI stays neutral with regard to jurisdictional clai$\mathrm{ms}$ in published maps and institutional affiliations.

Copyright: (C) 2021 by the authors. Licensee MDPI, Basel, Switzerland. This article is an open access article distributed under the terms and conditions of the Creative Commons Attribution (CC BY) license (https:// creativecommons.org/licenses/by/ $4.0 /)$.

\begin{abstract}
The role of the insulin receptor in mediating tissue-specific insulin clearance in vivo has not been reported. Using physiologic insulin doses, we measured the initial clearance rate (first $5 \mathrm{~min}$ ) of intravenously injected $\left(\left[{ }^{125} \mathrm{I}\right] \mathrm{Tyr}^{\mathrm{A}}{ }^{14}\right)$-insulin by muscle, liver, and kidney in healthy rats in the presence and absence of the insulin receptor blocker S961. We also tested whether 4 weeks of high-fat diet (HFD) affected the initial rate of insulin clearance. Pre-treatment with S961 for 60 min prior to administering labeled insulin raised plasma $\left(\left[{ }^{125} \mathrm{I}\right] \mathrm{Tyr}^{\mathrm{A} 14}\right)$ insulin concentration approximately 5-fold ( $p<0.001)$, demonstrating receptor dependency for plasma insulin clearance. Uptake by muscle $(p<0.01)$, liver $(p<0.05)$, and kidney $(p<0.001)$ were each inhibited by receptor blockade, undoubtedly contributing to the reduced plasma clearance. The initial plasma insulin clearance was not significantly affected by HFD, nor was muscle-specific clearance. However, HFD modestly decreased liver clearance $(p=0.056)$ while increasing renal clearance by $>50 \%(p<0.01)$, suggesting a significant role for renal insulin clearance in limiting the hyperinsulinemia that accompanies HFD. We conclude that the insulin receptor is a major mediator of initial insulin clearance from plasma and for its clearance by liver, kidney, and muscle. HFD feeding increases renal insulin clearance to limit systemic hyperinsulinemia.
\end{abstract}

Keywords: insulin clearance; insulin receptor; muscle; liver; kidney; S961

\section{Introduction}

Insulin activates signaling networks in many tissues by binding to the insulin receptor (IR) [1]. Insulin's action in the liver increases IR endocytosis and insulin clearance [2]. Kidney, muscle, adipose, brain, and other tissues also clear insulin $[3,4]$. The IR's role in systemic insulin clearance at these other sites has not been defined. We recently reported that S961 (a specific IR blocker), inhibits ([$\left.\left.{ }^{125} \mathrm{I}\right] \mathrm{Tyr}{ }^{\text {A14}}\right)$ insulin's initial brain clearance [5] by blocking insulin uptake by the brain microvascular endothelial cell [6], implicating vascular IRs in brain insulin clearance at physiological insulin concentrations. Unlabeled insulin, in vivo, inhibits skeletal muscle uptake of labeled insulin, indicating that insulin uptake is a saturable process [7], perhaps involving IR or insulin-like growth factor-1 (IGF-1) receptors (IGF-1R) or IR/IGF-1R hybrid receptors. Here, we used S961 (which specifically blocks IR, not IGF-1R or hybrid receptors) to test IR's role in whole-body (plasma) and tissue-specific (skeletal muscle, liver, and kidney) insulin clearance in rats. We also tested the effect of 4 weeks of high-fat diet (HFD) feeding on systemic and tissue-specific insulin clearance. HFD [8] and increased liver fat [9] inhibit liver insulin clearance, and its effect on insulin's clearance by other tissues has, to our knowledge, not been reported.

\section{Materials and Methods}

\subsection{Animal Study Protocol}

Two groups of male Sprague-Dawley rats were studied. Group 1 rats $(n=20$, weighing $275 \pm 8 \mathrm{~g})$ were fed a normal chow diet; group 2 rats $(n=14)$ were fed either a HFD $(60 \%$ of 
calories from fat, $n=7$, weight $444 \pm 8 \mathrm{~g}$ ) or chow ( $n=7$, weight $400 \pm 6 \mathrm{~g})$ for four weeks. The study protocols were approved by the University of Virginia Institutional Animal Care and Use Committee (protocol No. 4104, approved 14 November 2017). Overnight fasted rats were anesthetized with thiobutabarbital $(180 \mathrm{mg} / \mathrm{kg})$; both jugular veins were cannulated and used for either ([ $\left.{ }^{125} \mathrm{I}\right] \mathrm{Ty}$ A14)-insulin infusion or blood sampling. Rats were allowed to stabilize for $30 \mathrm{~min}$ after surgery before beginning the infusion study. Ten rats from group 1 were given $20 \mathrm{nmol} / \mathrm{kg}$ S961 intravenously $60 \mathrm{~min}$ before insulin administration [10], while control rats received only saline. S961 was generously provided by Novo-Nordisk, Copenhagen, Denmark.

\section{2. ([125. I]TyrA14) Insulin Administration and Analysis}

A 0.7 pmol $\left({ }^{125} \mathrm{I}\right] \mathrm{Tyr}^{\mathrm{A} 14}$ ) insulin (PerkinElmer, Waltham, MA, USA) bolus was delivered through the right jugular cannula, and subsequently, blood $(0.1 \mathrm{~mL} / \mathrm{min})$ was withdrawn every min through the left jugular cannula over $5 \mathrm{~min}$. With the rat deeply anesthetized, the left jugular vein was severed and the rat was perfused with ice-cold saline (5 mL/min for $12 \mathrm{~min}$ ). Skeletal muscle (quadriceps), kidney, and liver were quickly excised and frozen in liquid nitrogen. Blood and tissue samples were powdered, weighed, and mixed with $30 \%$ trichloroacetic acid (TCA) and centrifuged. After removing the supernatant, radioactivity in the tissue extracts was measured using a gamma counter (Packard, Cobra II, Canberra, Australia). TCA precipitation of radiolabeled insulin yields estimates of intact insulin comparable to that obtained by immune precipitation [11] but slightly greater than that reported by HPLC analysis [12]. However, given the short study time, and estimates that recirculating radiolabeled insulin degradation products contribute $<10 \%$ [12] of the total circulating radioactive species during the first 5 min following tracer injection, we opted to use the straightforward TCA precipitation method.

\subsection{Statistical Analysis}

For each study group, comparisons between treatments for plasma insulin clearance and for tissue-specific clearance were made using unpaired Student t-tests. A $p$-value less than 0.05 was considered significant.

\section{Results}

In group 1 , at $5 \mathrm{~min}$, only $5.2 \pm 0.6 \%$ of the labeled insulin remained in the plasma compartment in the control rats (estimated from the product of the measured plasma $\left.{ }^{[125} \mathrm{I}\right] \mathrm{Tyr}{ }^{\mathrm{A} 14}$-insulin at $5 \mathrm{~min}$ and estimated plasma volume divided by the injected dose) (Figure 1). Compared to the controls, plasma radioisotope retention was greater in S961treated animals $(24.1 \pm 2.4 \%$ at $5 \mathrm{~min}, p<0.001)$, indicating that IR blockade lowers whole-body insulin clearance. The doses of $\left[{ }^{125} \mathrm{I}\right] \mathrm{Tyr}{ }^{\mathrm{A} 14}$-insulin given here $(0.7 \mathrm{pmol})$ to $275-450 \mathrm{~g}$ rats, distributes to a plasma volume of $\sim 10-20 \mathrm{~mL}$, which would instantaneously augment plasma insulin concentrations by $\sim 35-70 \mathrm{pM}$, indicating that the initial insulin clearance rates reported here reflect physiologic insulin concentrations. In contrast to the marked effect of S961, for HFD-fed rats, plasma ${ }^{[125 I]}$ TyrA14-insulin retention was $4.8 \pm 0.9 \%$ and comparable to $5.0 \pm 0.4 \%$ in age-matched chow-fed controls, $p=0.84$. Thus, in these Sprague-Dawley rats, 4 weeks of HFD did not affect whole-body insulin clearance.

In control rats in group 1, insulin was cleared from plasma by muscle at a rate of $0.070 \pm 0.013 \mu \mathrm{L}(5 \mathrm{~min})^{-1} \mathrm{mg}^{-1}$, which decreased to $0.03 \pm 0.004 \mu \mathrm{L} / 5 \mathrm{~min} / \mathrm{mg}$ after S961 $(p=0.002)$ (Figure 2). Renal insulin clearance/mg tissue was much higher than either muscle or liver ( $p<0.001$, each comparison), and was inhibited by S961, $4.3 \pm 0.9$ vs $1.8 \pm 0.3 \mu \mathrm{L}(5 \mathrm{~min})^{-1} \mathrm{mg}^{-1}, p<0.001$ (Figure 3). Liver insulin clearance was also inhibited by IR blockade $\left(0.64 \pm 0.31\right.$ vs $\left.0.07 \pm 0.01 \mu \mathrm{L}(5 \mathrm{~min})^{-1} \mathrm{mg}^{-1} ; p=0.01\right)$ (Figure 4 ).

In group 2 rats, while plasma radiolabeled insulin retention did not differ between HFD and chow-fed rats, HFD increased renal insulin clearance compared with age-matched controls (5.2 \pm 0.6 vs $\left.2.8 \pm 0.5 \mu \mathrm{L}(5 \mathrm{~min})^{-1} \mathrm{mg}^{-1} ; p<0.01\right)$. Initial liver insulin clearance was approximately $30 \%\left(0.39 \pm 0.06\right.$ and $\left.0.6 \pm 0.10 \mu \mathrm{L}(5 \mathrm{~min})^{-1} \mathrm{mg}^{-1}\right)$ less with HFD, 
but this change was of borderline statistical significance $(p=0.056)$. Skeletal muscle's initial insulin clearance was unaffected by HFD compared to age-matched chow diet rats $\left(0.070 \pm 0.010\right.$ vs. $0.078 \pm 0.007 \mu \mathrm{l}\left(5 \mathrm{~min}^{-1} \mathrm{mg}^{-1}\right.$, respectively; $\left.p=0.7\right)$.

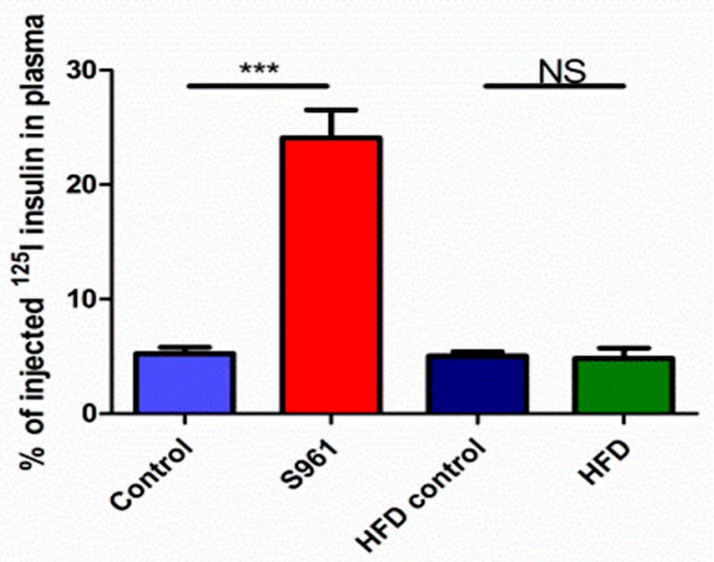

Figure 1. Plasma content of 125 iodine remaining in plasma at five minutes after injection in animal studied under protocol 1 (left two bars) and protocol 2 (right two bars). ${ }^{* * *}$ Indicates $p$ value less than 0.001 unpaired t-test.
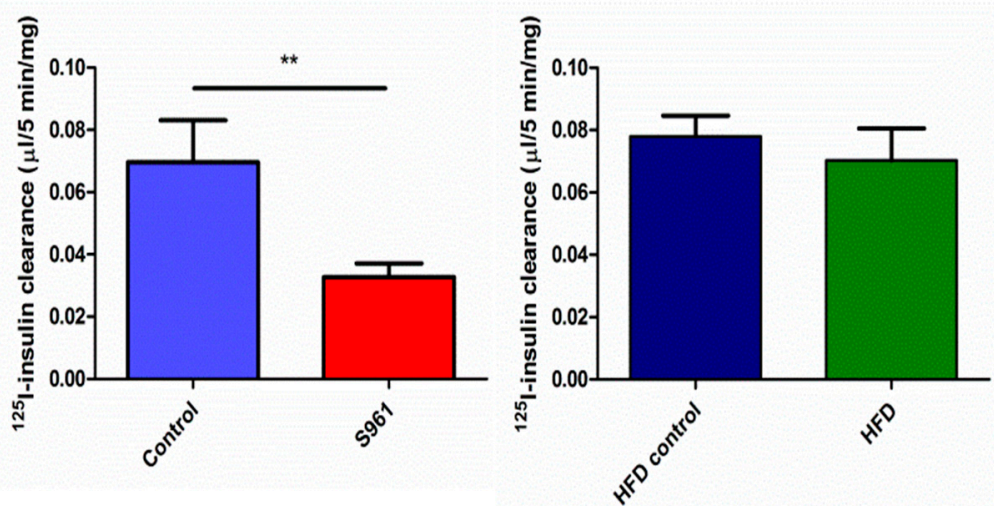

Figure 2. Clearance of radiolabeled insulin by skeletal muscle in rats studied + / -S961 under protocol 1 (left panel) or after feeding a chow diet (blue) or a high-fat diet (green) for four weeks (right panel). ** indicates significance $(p<0.01)$.
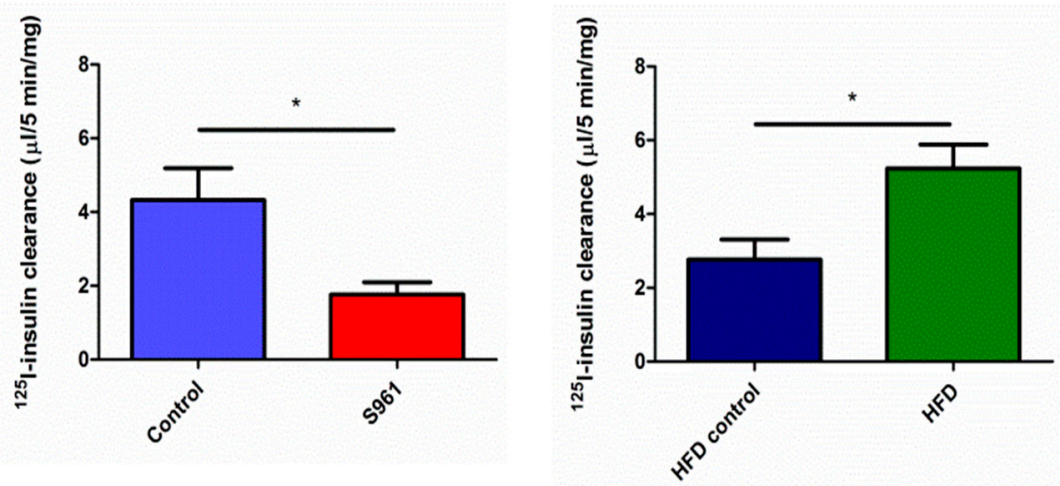

Figure 3. Kidney radiolabeled insulin clearance in rats studied under protocol 1 (left panel) or protocol 2 (right panel). S961 significantly decreased kidney radiolabeled insulin uptake $\left({ }^{*} ; p<0.002\right)$. By contrast, high-fat diet significantly increased insulin clearance $(p<0.002)$. 

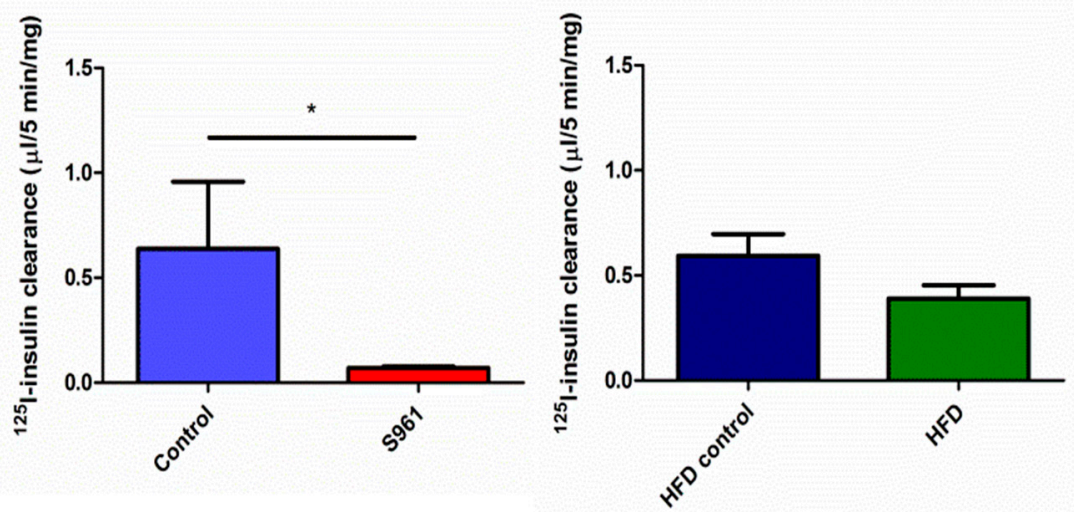

Figure 4. Liver radiolabeled insulin clearance in rats studied under protocol 1 (left panel) or protocol 2 (right panel). S961 significantly decreased radiolabeled insulin uptake ( ${ }^{*} ; p=0.01$ ), while high-fat diet provoked a downward trend in hepatic insulin clearance $(p=0.056)$. Liver radiolabeled insulin clearance in rats studied under protocol 1 (left panel) or protocol 2 (right panel). S961 significantly decreased radiolabeled insulin uptake, and high-fat diet provoked a downward trend in hepatic insulin clearance $(p=0.056)$.

\section{Discussion}

Here, we first used the IR specificity of S961 to test whether IRs facilitated the initial rate of whole-body as well as hepatic, renal, and skeletal muscle insulin clearance in vivo. The first step in insulin's clearance from plasma involves its distribution via the circulation through the plasma compartment. It can then bind to accessible binding sites (e.g., insulin or IGF-1 receptors) on the vascular endothelium or on the liver (whose fenestrated endothelium allows more direct contact of plasma to hepatocytes). In tissues with a continuous endothelium, insulin binding is followed by crossing the vessel wall which separates plasma from the tissue interstitial fluid. In this study, by measuring clearance over a short, $5 \mathrm{~min}$ interval using physiologically relevant insulin concentrations, we intentionally sought to assess tissue contributions to these initial steps of insulin clearance. In support of this, in human studies, Sherwin et al. [13] found that a 3-compartment model -with plasma as the compartment that fills immediately, liver (splanchnic) next, and muscle more slowlyadequately described the kinetics of injected insulin's plasma appearance and clearance. In the rat, Philippe et al. used ${ }^{3} \mathrm{H}$-labeled insulin [14] and found that insulin's initial volume of distribution (Vd) was greater in the streptozotocin (STZ) diabetic vs control animals. Pre-treating the diabetic rats with a single dose of unlabeled insulin eliminated this difference, suggesting that the initial Vd includes a binding component that was blocked by the unlabeled insulin. Additionally, unlabeled insulin given 6 min after injection of labeled insulin immediately raised the plasma labeled insulin concentration, indicating the competitive displacement of the label from binding sites accessible to plasma. Others have also seen this displacement of insulin from reversible vascular binding sites $[11,15]$ in non-diabetic animals.

The capillary endothelium forms a barrier with a permeability that varies widely across organs. The liver is responsible for the bulk of endogenous insulin clearance, partly through a first-pass effect. This process is likely mediated by IRs on the hepatocyte, given the highly permeable, fenestrated hepatic endothelium. Underscoring the hepatocyte IR's role (as opposed to the hepatic endothelial cell (EC) IRs) for liver insulin clearance, hepatocyte-specific expression of a dominant-negative carcinoembryonic antigen-related cell adhesion molecule 1 (CEACAM1), which is necessary for liver cell IR and insulin internalization, inhibits insulin clearance, provoking hyperinsulinemia and metabolic insulin resistance [2]. Current data show that $\mathrm{S} 961$ decreased liver uptake of labeled insulin by $\sim 85 \%$, an effect greater than we found in muscle or kidney, or previously in the brain [5], confirming the critical role for hepatocyte IRs in hepatic insulin clearance. HFD decreased 
liver insulin clearance by $\sim 30 \%$, which is comparable to the decline of insulin clearance by perfused livers of rats fed HFD for 3.5 weeks [16].

Muscle, unlike the liver, has a relatively tight, continuous endothelium, which must be crossed for insulin to act on target myocytes [17]. In the kidney, insulin must either cross the glomerular fenestrated capillaries and be taken up from the tubular lumen or cross the capillary in post-glomerular peritubular capillaries [18]. Crossing the endothelium likely poses a rate-limiting barrier to insulin clearance by muscle or kidney and clearly does so in the brain, limited by the blood-brain barrier [5]. Vascular ECs can transport insulin, albumin, and other proteins across the vessel wall [19-21]. The demonstrated effect of S961 to decrease insulin clearance from plasma underscores the IR's importance to whole-body insulin kinetics while its inhibition of liver, muscle, and renal uptake indicates IR involvement in insulin clearance by multiple tissues.

Insulin clearance by the kidney (per gram of tissue) exceeds that of any other organ [18]. Arteriovenous differences in insulin concentration are 30\% in men [22]. However, only a small portion of the filtered load appears in urine, the rest is degraded [23]. In the kidney, insulin clearance is complex as insulin may enter the renal cortical cells either by crossing the vascular endothelium of peritubular capillaries or via reabsorption from the tubular lumen after crossing the fenestrated endothelium of the glomerulus. The latter process appears to be mediated by Low density lipoprotein receptor-related protein 2(LRP-2 or megalin), a multi-ligand binding receptor, not IR [24]. Both the short 5 min time-interval of labeled insulin exposure and the observed dramatic impact of S961 to reduce renal tracer uptake suggest that in the current studies, S961 is acting principally on the peritubular capillary. The finding that HFD increases the initial rate of renal insulin clearance may indicate a compensatory role for the kidney to limit peripheral hyperinsulinemia seen with HFD feeding. Renal blood flow increases with HFD feeding as does GFR. The increased renal flow may contribute to the increased insulin clearance seen here in the HFD rats.

The inhibition of muscle insulin clearance by $\mathrm{S} 961$ supports the hypothesis that IRs, likely at the microvascular EC, mediate muscle insulin uptake. This is in accord with prior work demonstrating transcellular insulin movement across the EC in skeletal muscle microvasculature [20] and that this process is saturable [7]. By contrast, a recent study tracing transport of fluorescent-tagged insulin across mouse muscle capillaries suggested that IRs were not involved, rather favoring insulin's passive movement with bulk fluid transport [25]. However, the insensitivity of the fluorescence method employed in those studies necessitated the use of high insulin doses ( $2-4 \mathrm{U} / \mathrm{kg}$ body weight) with resulting plasma insulin concentrations estimated $>10,000 \mu \mathrm{U} / \mathrm{mL}$. This would far exceed the saturation of IR binding and favor the bulk fluid movement pathway reported. Indeed, recent work using adipose microvascular endothelial cells directly confirms two distinct pathways for endothelial cell insulin uptake with IR-mediated transport at physiological insulin concentrations and fluid-phase transport with pharmacologic insulin concentrations [26].

We previously measured steady-state clearance of endogenous insulin by forearm skeletal muscle in fasting humans $(0.0190 \mu \mathrm{L} / 5 \mathrm{~min} / \mathrm{mg}$ tissue, and during a $1 \mathrm{mU} / \mathrm{min} / \mathrm{kg}$ euglycemic insulin clamp [27]. We reported a significant decline in skeletal muscle insulin clearance during physiologic hyperinsulinemia, indicative of a saturable transport process. Given the significant saturation of clearance with hyperinsulinemia, the involvement of the insulin receptor seemed likely. The current finding that $\mathrm{S} 961$ blocks muscle insulin uptake supports that involvement.

The lack of effect of HFD on muscle insulin clearance was perhaps unexpected since insulin-induced muscle microvascular recruitment is blunted after 2 weeks HFD [26]. This suggests that HFD may be acting at a downstream insulin signaling, not on binding per se. Therefore, tissue EC insulin uptake may be affected later than vasorelaxation or not be affected at all. It is also possible that the less abundant perfusion of muscle $(\sim 1 / 20$ th that of liver, kidney, or brain on a flow/g tissue basis) decreased our ability to detect modest changes in tracer uptake in these short-duration studies. 
It is interesting to compare the clearance of insulin by the tissue studied here with known rates of insulin delivery to these tissues as indicated by their respective tissue blood flows. We did not measure tissue-specific blood flow in the current study. However, representative values for barbiturate anesthetized, healthy rats from multiple published studies are available. Table 1 illustrates the relationships between blood flow to each tissue and insulin clearance values. The extraction ratio for insulin is also given. Since all tissues studied received the same arterial concentration of labeled insulin throughout the five min infusion, the tissue extraction ratio can be calculated simply from the tissue blood flow divided by the insulin clearance. We included data on brain insulin clearance which we previously published [5]. The similar extraction ratio (18-20\%) by kidney and muscle, despite very different blood flows per gram tissue, underscores the importance of insulin delivery for its clearance. The somewhat lower extraction ratio for the liver may be due to the fact that liver extraction of labeled insulin is competing with the portal rather than the systemic insulin concentration. The former being 2-3-fold higher in concentration, the lower extraction ratio would be expected in a saturable system. Brain insulin clearance appears to be the outlier, the brain having a much more robust blood flow than muscle but a comparable insulin clearance. As a result, its extraction ratio is only $1 / 10$ that of either muscle, kidney, or likely liver (the latter were corrected for portal insulin concentration).

Table 1. Tissue-specific blood flow, insulin clearance, and extraction ratio from rats studied under protocol 1 not treated with S961. Data for brain blood flow, clearance, and extraction ratio (ER) are provide for comparison.

\begin{tabular}{cccc}
\hline Tissue & Blood Flow & Insulin Clearance & Extraction Ratio \\
\hline Skeletal muscle & $0.06-0.07$ & 0.07 & $(\%)$ \\
\hline Kidney & $5-6$ & 4.3 & $\sim 20 \%$ \\
\hline Brain (Cortex) & 0.8 & 0.07 & $\sim 18 \%$ \\
\hline Liver & 1.4 & 0.64 & $\sim 1.75 \%$ \\
\hline
\end{tabular}

Clearly, the endothelium of the blood-brain barrier is substantially more restrictive than that of the other tissues studied here. However, S961 lowers insulin's clearance by all tissues, underscoring the important role of the insulin receptor.

\section{Conclusions}

The endothelial IR rapidly binds insulin and facilitates its clearance by skeletal muscle and kidney. Four weeks of HFD does not affect muscle insulin clearance but may blunt liver clearance and significantly increases renal clearance. The latter may be an adaptation that limits hyperinsulinemia and secondary insulin resistance.

Author Contributions: R.I.M. participated in experimental design, study conduct, data analysis, and manuscript preparation; E.J.B. participated in experimental design, data analysis, manuscript presentation, and study funding. All authors have read and agreed to the published version of the manuscript.

Funding: NIH NHLBI RO1HL142250 (to E.J.B.).

Institutional Review Board Statement: The University of Virginia Animal Care \& Use Committee (ACUC) reviewed and approved the animal protocol (protocol No. 4104 approved 14 November 2017).

Data Availability Statement: Primary data are available from the corresponding author upon reasonable request.

Conflicts of Interest: The authors declare no conflict of interest. 


\section{References}

1. Konishi, M.; Sakaguchi, M.; Lockhart, S.M.; Cai, W.; Li, M.E.; Homan, E.P.; Rask-Madsen, C.; Kahn, C.R. Endothelial insulin receptors differentially control insulin signaling kinetics in peripheral tissues and brain of mice. Proc. Natl. Acad. Sci. USA 2017, 114, E8478-E8487. [CrossRef] [PubMed]

2. Najjar, S.M.; Perdomo, G. Hepatic insulin clearance: Mechanism and physiology. Physiology 2019, 34, 198-215. [CrossRef] [PubMed]

3. Duckworth, W.C.; Bennett, R.G.; Hamel, F.G. Insulin degradation: Progress and potential 1. Endocr. Rev. 1998, 19, 608-624. [PubMed]

4. Polonsky, K.S.; Given, B.D.; Hirsch, L.; Shapiro, E.T.; Tillil, H.; Beebe, C.; Galloway, J.A.; Frank, B.H.; Karrison, T.; Van Cauter, E. Quantitative study of insulin secretion and clearance in normal and obese subjects. J. Clin. Investig. 1988, 81, 435. [CrossRef] [PubMed]

5. Meijer, R.I.; Gray, S.M.; Aylor, K.W.; Barrett, E.J. Pathways for insulin access to the brain: The role of the microvascular endothelial cell. Am. J. Physiol. 2016, 311, H1132-H1138. [CrossRef] [PubMed]

6. Gray, S.M.; Aylor, K.W.; Barrett, E.J. Unravelling the regulation of insulin transport across the brain endothelial cell. Diabetologia 2017, 60, 1512-1521. [CrossRef]

7. Majumdar, S.; Genders, A.J.; Inyard, A.C.; Frison, V.; Barrett, E.J. Insulin entry into muscle involves a saturable process in the vascular endothelium. Diabetologia 2012, 55, 450-456. [CrossRef]

8. Svedberg, J.; Stromblad, G.; Wirth, A.; Smith, U.; Bjorntorp, P. Fatty acids in the portal vein of the rat regulate hepatic insulin clearance. J. Clin. Investig. 1991, 88, 2054-2058. [CrossRef]

9. Kotronen, A.; Vehkavaara, S.; Seppälä-Lindroos, A.; Bergholm, R.; Yki-Järvinen, H. Effect of liver fat on insulin clearance. Am. J. Physiol. 2007, 293, E1709-E1715. [CrossRef]

10. Schäffer, L.; Brand, C.L.; Hansen, B.F.; Ribel, U.; Shaw, A.C.; Slaaby, R.; Sturis, J. A novel high-affinity peptide antagonist to the insulin receptor. Biochem. Biophys. Res. Commun. 2008, 376, 380-383. [CrossRef]

11. Zeleznik, A.J.; Roth, J. Demonstration of the insulin receptor in vivo in rabbits and its possible role as a reservoir for the plasma hormone. J. Clin. Investig. 1978, 61, 1363-1374. [CrossRef] [PubMed]

12. Sato, H.; Tsuji, A.; Hirai, K.-I.; Kang, Y.S. Application of HPLC in Disposition Study of A14- ${ }^{125}$ I-Labeled Insulin in Mice. Diabetes 1990, 39, 563-569. [CrossRef] [PubMed]

13. Sherwin, R.S.; Kramer, K.J.; Tobin, J.D.; Insel, P.A.; Liljenquist, J.E.; Berman, M.; Andres, R. A model of the kinetics of insulin in man. J. Clin. Investig. 1974, 53, 1481-1492. [CrossRef] [PubMed]

14. Philippe, J.; Halban, P.A.; Gjinovci, A.; Duckworth, W.C.; Estreicher, J.; Renold, A.E. Increased Clearance and Degradation of [3 H] Insulin in Streptozotocin Diabetic Rats: Role of the insulin receptor compartment. J. Clin. Investig. 1981, 67, 673-680. [CrossRef] [PubMed]

15. Rasio, E.A. The displacement of insulin from blood capillaries. Diabetologia 1969, 5, 416-419. [CrossRef]

16. Strömblad, G.; Björntorp, P. Reduced hepatic insulin clearance in rats with dietary-induced obesity. Metab. Clin. Exp. 1986, 35, 323-327. [CrossRef]

17. Aird, W.C. Phenotypic heterogeneity of the endothelium: II. Representative vascular beds. Circ. Res. 2007, 100, 174-190. [CrossRef]

18. Rubenstein, A.H.; Spitz, I. Role of the kidney in insulin metabolism and excretion. Diabetes 1968, 17, 161-169. [CrossRef]

19. King, G.L.; Johnson, S.M. Receptor-mediated transport of insulin across endothelial cells. Science 1985, 227, 1583-1586. [CrossRef]

20. Wang, H.; Liu, Z.; Li, G.; Barrett, E.J. The vascular endothelial cell mediates insulin transport into skeletal muscle. Am. J. Physiol. Endocrinol. Metab. 2006, 291, E323-E332. [CrossRef]

21. John, T.A.; Vogel, S.M.; Tiruppathi, C.; Malik, A.B.; Minshall, R.D. Quantitative analysis of albumin uptake and transport in the rat microvessel endothelial monolayer. Am. J. Physiol. Lung Cell Mol. Physiol. 2003, 284, L187-L196. [CrossRef] [PubMed]

22. Ferrannini, E.; Wahren, J.; Faber, O.K.; Felig, P.; Binder, C.; DeFronzo, R. Splanchnic and renal metabolism of insulin in human subjects. Am. J. Physiol. Endocrinol. Metab. 1983, 244, E517-E527. [CrossRef] [PubMed]

23. Rabkin, R.; Ryan, M.P.; Duckworth, W.C. The renal metabolism of insulin. Diabetologia 1984, 27, 351-357. [CrossRef] [PubMed]

24. Orlando, R.A.; Rader, K.; Authier, F.; Yamazaki, H.; Posner, B.I.; Bergeron, J.J.; Farquhar, M.G. Megalin is an endocytic receptor for insulin. J. Am. Soc. Nephrol. 1998, 9, 1759-1766. [PubMed]

25. Williams, I.M.; Valenzuela, F.A.; Kahl, S.D.; Ramkrishna, D.; Mezo, A.R.; Young, J.D.; Wells, K.S.; Wasserman, D.H. Insulin exits skeletal muscle capillaries by fluid-phase transport. J. Clin. Investig. 2018, 128, 699-714. [CrossRef]

26. Jaldin-Fincati, J.R.; Pereira, R.V.; Bilan, P.J.; Klip, A. Insulin uptake and action in microvascular endothelial cells of lymphatic and blood origin. Am. J. Physiol.-Endocrinol. Metab. 2018, 315, E204-E217. [CrossRef]

27. Eggleston, E.M.; Jahn, L.A.; Barrett, E.J. Hyperinsulinemia Rapidly Increases Human Muscle Microvascular Perfusion but Fails to Increase Muscle Insulin Clearance: Evidence That a Saturable Process Mediates Muscle Insulin Uptake. Diabetes 2007, 56, 2958-2963. [CrossRef] [PubMed] 